\title{
Badania eksperymentalne wpływu geometrii na sygnał diagnostyczny w metodzie magnetycznej pamięci metalu
}

\section{Experimental studies of the impact of geometry on the diagnostic signal in the metal magnetic memory testing method}

\section{Streszczenie}

Dla próbek ze stali 16 Mo3 badano wpływ geometrii na wartości składowych wektora natężenia własnego magnetycznego pola rozproszonego WMPR oraz na wartości ich gradientów. Stwierdzono dobrą relację składowej stycznej WMPR mierzonej w kierunku działania naprężeń głównych z wartościami zadawanych obciążeń. Widoczny jest wpływ geometrii próbek, lecz ilościowo jest on niewielki w stosunku do zmian wartości wywołanych obciążeniami. Natomiast wpływ geometrii próbek na wartości gradientów jest znaczący. Nie można tego wpływu pomijać przy opracowywaniu wartości granicznych kryteriów oceny w metodzie MPM, stąd też metodyka tej metody wymaga poprawy i uzupełnienia.
Abstract

The impact of geometry on the values of the residual magnetic field (RMF) strength vector components and on the values of their gradients was studied for $16 \mathrm{Mo} 3$ steel samples. A good correlation was found between the RMF tangential component measured in the direction of principal stress and the values of pre-set loads. The sample geometry impact is visible but in terms of quantity it is slight compared to the changes in values induced by varying loads. However, the impact of the sample geometry on the value of gradients is significant. This impact must not be ignored while developing boundary values of evaluation criteria in the MMM testing method, whose methodology should therefore be improved and supplemented.

\section{Wstęp i cel badań}

Sygnałem diagnostycznym w metodzie magnetycznej pamięci metalu MPM są składowe wektora natężenia własnego magnetycznego pola rozproszonego WMPR (oraz ich gradienty) zmierzone na powierzchni badanego elementu [1]. WMPR elementu wynika z jego cech konstrukcyjnych (geometrycznej, tworzywowej i dynamicznej), historii eksploatacji i usytuowania w zewnętrznym polu magnetycznym [2]. Cechy

Dr inż. Maciej Roskosz, mgr inż. Mateusz Dedyk, inż. Anna Soltysik - Politechnika Śląska. konstrukcyjne elementu decydują o tym, że na jego powierzchni, przy określonej orientacji w danym otoczeniu magnetycznym, powstaje unikatowy rozkład

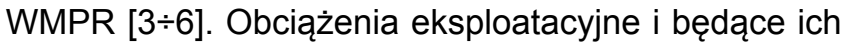
skutkiem procesy zużycia wpływają na tworzywową i dynamiczną cechę konstrukcyjną, a przez to na zmianę rozkładu WMPR. Obserwacja i analiza tych zmian, połączona z oceną stopnia wytężenia i/lub stopnia zużycia, umożliwia opracowanie ilościowych kryteriów

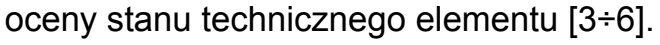

W niniejszym opracowaniu, dla określonego wytężenia, analizowano wpływ cechy geometrycznej elementu na wartości składowych WMPR i ich gradientów. Analiza ta będzie etapem opracowania ogólnej metodyki 
określania ilościowych kryteriów oceny opartych na WMPR jako sygnale diagnostycznym. Kryteria te mogą znaleźć zastosowanie zarówno w badaniach metodą MPM jak i również w monitorowaniu stanu konstrukcji stalowych $[3 \div 7]$.

\section{Metodyka badań}

Badano próbki płytowe ze stali 16Mo3, których geometrię pokazano na rysunku 1. Próbki, przy jednakowej długości całkowitej (550 mm) i jednakowej długości przewężenia $(80 \mathrm{~mm})$ oraz stałym wymiarze ich szerszych części $A=50 \mathrm{~mm}$, różniły się wymiarem szerokości przewężenia B. Badano trzy grupy próbek o wymiarze B wynoszącym odpowiednio 20, 30 i $40 \mathrm{~mm}$.

Próbki były obciążane za pomocą maszyny wytrzymałościowej Galdabini Sun 10P. Po osiągnięciu zadanych obciążeń próbki były odciążane i badane poza maszyną. Obciążenie dobierano tak, by w przewężeniu próbki występowały jednakowe wartości naprężeń rozciągających dla poszczególnych grup próbek. Umożliwia to porównanie rozkładów składowych WMPR na linii pomiarowej, przy takim samym poziomie naprężeń w przewężeniu, dla różnych grup próbek.

Do badań wykorzystywano magnetometr TSC-1M-4 z głowicą pomiarową TSC-2M dostarczony przez Energodiagnostika Co. Ltd Moscow.

Mierzono dwie składowe WMPR na powierzchni próbki (rys. 1):

- $\mathrm{H}_{\mathrm{T}, \mathrm{Y}}$ - składowa styczna mierzona w kierunku równoległym do kierunku zadawanego obciążenia,

- $\mathrm{H}_{\mathrm{N}, \mathrm{Z}}$ - składowa normalna.

\section{Wyniki badań}

Na rysunku 2 przedstawiono przykładowe, reprezentatywne rozkłady składowych WMPR na linii pomiarowej próbek, różniących się geometrią przewężenia (różne wartości wymiaru B z rysunku 1).

Na rysunkach $2 a$ i $2 b$ pokazano zmierzone po odciążeniu, rozkłady składowych WMPR po wywołaniu w węższej części próbki naprężeń rozciągających $\sigma=50 \mathrm{MPa}$. Widoczna jest zmiana rozkładów składowych WMPR w stosunku do stanu początkowego.
W każdej z próbek wyraźnie zaznacza się zróżnicowanie naprężeń pomiędzy przewężeniem a pozostałą częścią próbki.

Analizując rozkłady składowej stycznej $\mathrm{H}_{\mathrm{TY}}$ (rys. 2a), dla tego samego poziomu naprężenia w przewężeniu, występują różnice jej wartości. Pomijając wpływ innych czynników (niejednorodności struktury, anizotropii, pojawiających się naprężeń resztkowych), można założyć, że zróżnicowanie to jest głównie wynikiem wpływu geometrii próbek. Może ono wynikać również z wartości naprężeń występujących w pozostałej części próbki. Dla $\sigma=50 \mathrm{MPa}$ w przewężeniu, w szerszych częściach próbek występują następujące naprężenia:

a) $\mathrm{B}=20 \mathrm{~mm}-\sigma=20 \mathrm{MPa}$,

b) $\mathrm{B}=30 \mathrm{~mm}-\sigma=30 \mathrm{MPa}$,

c) $\mathrm{B}=40 \mathrm{~mm}-\sigma=40 \mathrm{MPa}$.

Na rysunku 2a widać, że najmniejszym naprężeniom odpowiadają najmniejsze zmiany wartości składowej stycznej $\mathrm{H}_{\mathrm{TY}}$ w stosunku do wartości początkowych. Widać również, że wpływ naprężeń na wartości składowej stycznej $\mathrm{H}_{\mathrm{T} Y}$ jest silnie nieliniowy.

Naprężenia te wpływają na zmiany trendu składowej normalnej $\mathrm{H}_{\mathrm{N}, \mathrm{Z}}$ (rys. 2b) na linii pomiarowej. Jej wartości nie nadają się jednak do oceny stanu wytężenia, ponieważ przykładowo, dla próbki o szerokości $\mathrm{B}=20 \mathrm{~mm}$, w obszarze przewężenia przyjmuje ona wartości od -160 do -10 A/m. Natomiast można stwierdzić, że im większe naprężenia, tym większy gradient zmian składowej normalnej $\mathrm{H}_{\mathrm{N}, \mathrm{Z}}$.

Rysunki 2c i 2d przedstawiają, zmierzone po odciążeniu, rozkłady składowych WMPR po wywołaniu w węższej części próbki naprężeń rozciągających ( $\sigma=375 \mathrm{MPa}$ ) wyższych od granicy plastyczności i wywołujących znaczne odkształcenia plastyczne. W tym przypadku wpływ geometrii próbek jest wyraźnie widoczny w rozkładach obydwu analizowanych składowych WMPR. W próbkach o największym zróżnicowaniu przekrojów występują największe zmiany WMPR, a wraz ze zmniejszaniem się tej różnicy zmiany WMPR maleją. Trend zmian, który zarysował się w początkowej fazie obciążania, pozostaje niezmieniony.

Pojawia sie pytanie: który z czynników wpływu, naprężenia czy geometria, jest dominujący w zmianach wartości składowej stycznej $\mathrm{H}_{\mathrm{T}, \mathrm{Y}}$ Aby odpowiedzieć na to pytanie przeanalizowano zmiany średnich wartości składowej stycznej $\mathrm{H}_{\mathrm{T}, \mathrm{Y}}$ na odcinku od 90 do 110 $\mathrm{mm}$ linii pomiarowej w zależności od zadanego wcześniej obciążenia. Zależność średnich wartości składowej stycznej $\mathrm{H}_{\mathrm{T}, \mathrm{Y}}$ od naprężeń pokazano na rysunku 3.

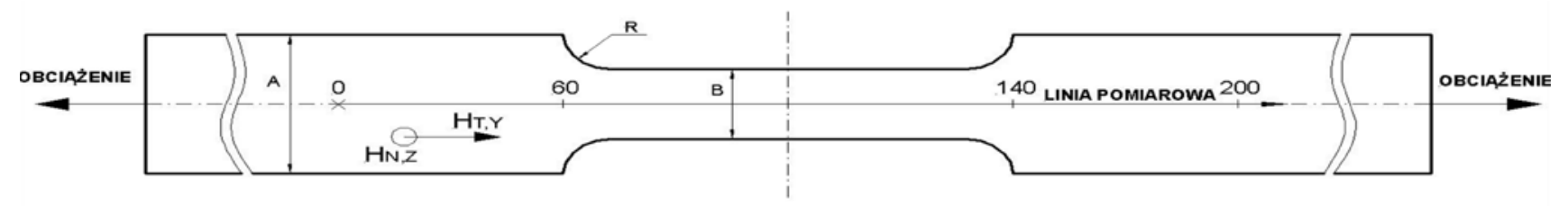

Rys. 1. Próbka do badań

Fig. 1. Experimental sample 
a)

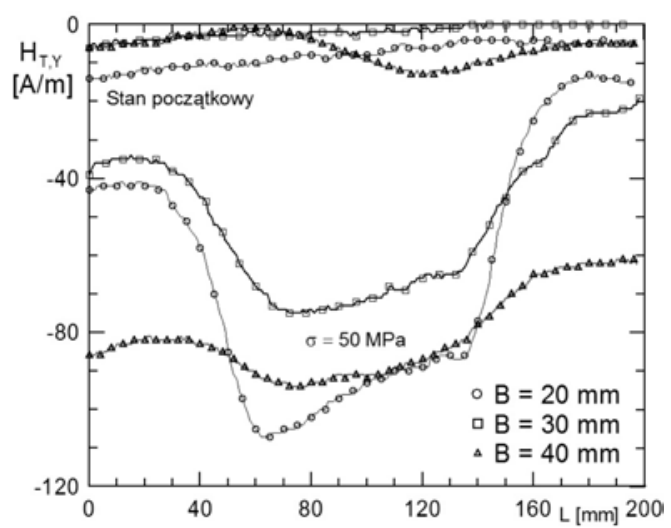

b)

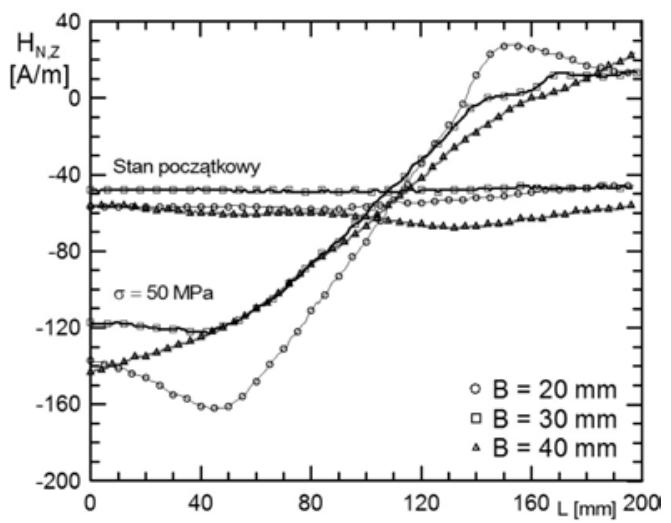

c)

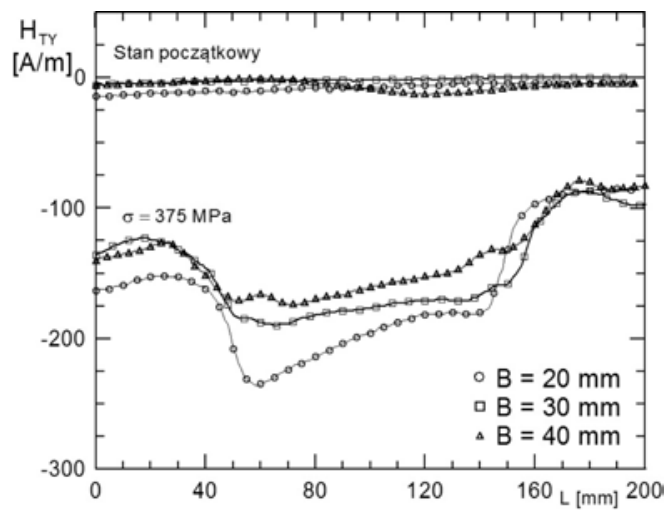

d)

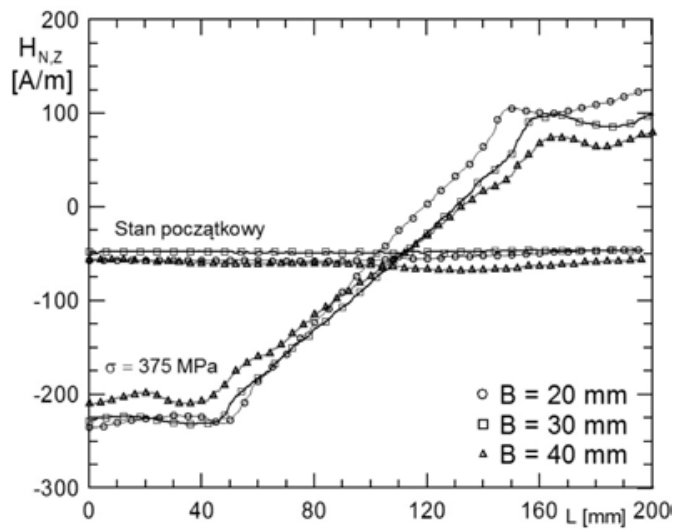

Rys. 2. Rozkłady składowych WMPR na linii pomiarowej dla dwóch poziomów naprężeń rozciągających - pomiar po odciążeniu: a) $\sigma=50 \mathrm{MPa}$, składowa styczna $\mathrm{H}_{\mathrm{T}, \mathrm{Y}}$, b) $\sigma=50 \mathrm{MPa}$, składowa normalna $\left.\mathrm{H}_{\mathrm{N}, \mathrm{Z}}, \mathrm{c}\right) \sigma=375 \mathrm{MPa}$, składowa styczna $\left.\mathrm{H}_{\mathrm{T},}, \mathrm{d}\right) \sigma=375 \mathrm{MPa}$, składowa normalna $\mathrm{H}_{\mathrm{N}, \mathrm{Z}}$

Fig. 2. Distributions of the RMF components on the measurement line for two levels of tensile stress - measurement after unloading: a) $\sigma=50 \mathrm{MPa}$, tangential component $\mathrm{H}_{\mathrm{T}}$, b) $\sigma=50 \mathrm{MPa}$, normal component $\left.\mathrm{H}_{\mathrm{N}, \mathrm{Z}}, \mathrm{C}\right) \sigma=375 \mathrm{MPa}$, tangential component $\mathrm{H}_{\mathrm{T}, \mathrm{Y}}$ d) $\sigma=375 \mathrm{MPa}$, normal component $\mathrm{H}_{\mathrm{N}, \mathrm{Z}}$

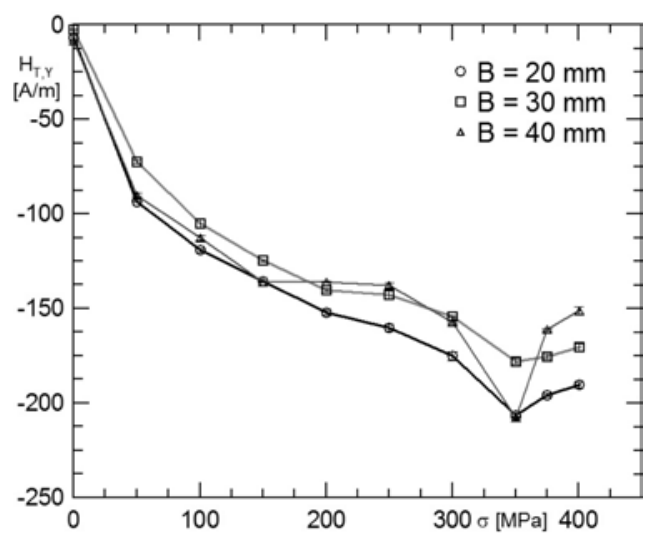

Rys. 3. Zależność średnich wartości składowej stycznej $H_{T, Y}$ od naprężeń rozciągających - pomiar po odciążeniu

Fig. 3. Dependence of the average values of tangential component $\mathrm{H}_{\mathrm{T}, \mathrm{Y}}$ on tensile stress - measurement after unloading

Widać, że w analizowanych przypadkach dominuje wpływ naprężeń, choć wpływ geometrii też jest widoczny.

llościowe kryteria oceny w metodzie MPM są oparte na gradientach składowych WMPR. W $[8,9]$ wykazano błędy i niejasności w metodyce MPM [10,11] związane ze stosowanym do oceny stanu materiału indeksem magnetycznym (będącym stosunkiem lokalnego maksimum gradientu do wartości średniej $w$ badanym elemencie) oraz sposobem określania jego wartości granicznych. W normie [10] mowa jest tylko o „specjalnej procedurze” wyznaczania wartości granicznych indeksu magnetycznego, a z kolei w opracowaniu [11] wiąże się wartość graniczną $z$ właściwościami wytrzymałościowymi - tworzywową cechą konstrukcyjną, pomijając zupełnie wpływ pozostałych (geometrycznej i dynamicznej). Stąd też szczególnie interesującym zagadnieniem jest wpływ geometrii elementu na wartości gradientów dla różnych stanów wytężenia.

Na rysunkach $4 \mathrm{a}$ i $4 \mathrm{~b}$ oraz $5 \mathrm{a}$ i $5 \mathrm{~b}$ pokazano wpływ naprężeń i geometrii na wartości maksymalne gradientów składowych WMPR, które występują w strefach zmiany przekroju (rys. 4a i 4b) oraz na wartości średnie gradientów składowych WMPR wyznaczone dla obszaru o stałym przekroju na odcinku pomiędzy 90. a 110. punktem na linii pomiarowej próbki (rys. 5a i 5b). Na rysunkach tych wpływ geometrii na gradienty jest wyraźnie widoczny, zarówno w ujęciu ilościowym, jak i jakościowym. Zamieszczone na rysunkach linie trendu pokazują, że geometria może nawet wpływać na zmiany gradientów. Szczególnie widoczne jest to na rysunku $5 \mathrm{~b}$, gdzie $\mathrm{w}$ zakresie naprężeń od 0 do $300 \mathrm{MPa}$ dla $\mathrm{B}=20 \mathrm{~mm}$ występuje trend wzrostowy, a dla próbek o wymiarze $B$ równym 30 i $40 \mathrm{~mm}$ wartości gradientów najpierw wzrastają, a po przekroczeniu $200 \mathrm{MPa}$ maleją. Ilościowo rzecz ujmując, im większy jest stosunek przekrojów, tym większe są wartości gradientów średnich i maksymalnych. 
a)

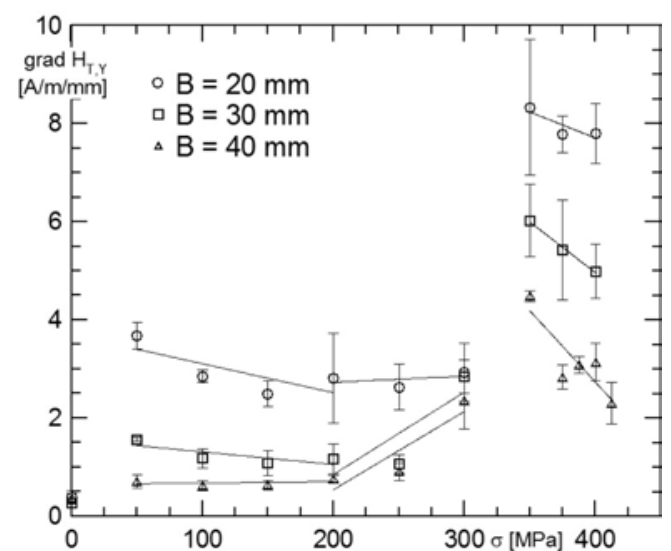

b)

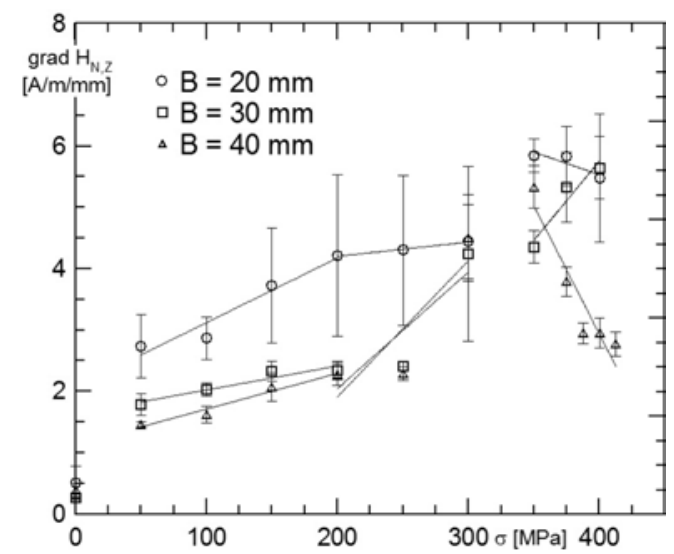

Rys. 4. Zależność maksymalnych wartości gradientów składowych WMPR od naprężeń rozciągających - pomiar po odciążeniu: a) gradient maksymalny składowej stycznej $H_{T Y}$, b) gradient maksymalny składowej normalnej $H_{N, Z}$

Fig. 4. Dependence of the maximum values of gradients of the RMF components on tensile stress - measurement after unloading: a) maximum gradient of the tangential component $\mathrm{H}_{\mathrm{T}, \mathrm{Y}}$, b) maximum gradient of the normal component $\mathrm{H}_{\mathrm{N}, \mathrm{Z}}$

a)

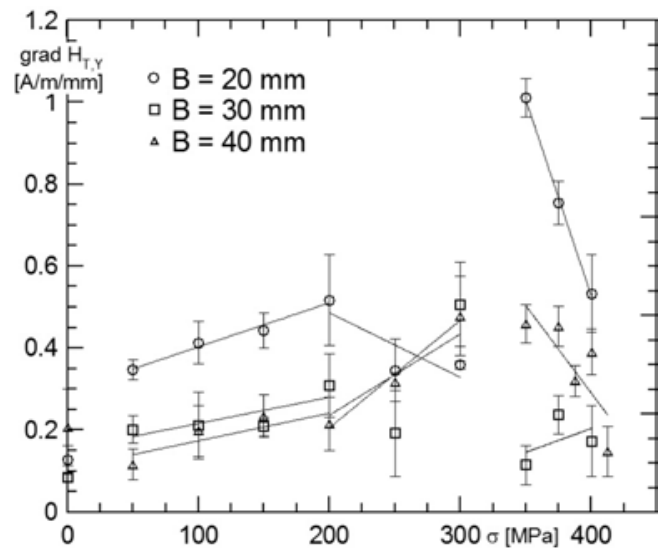

b)

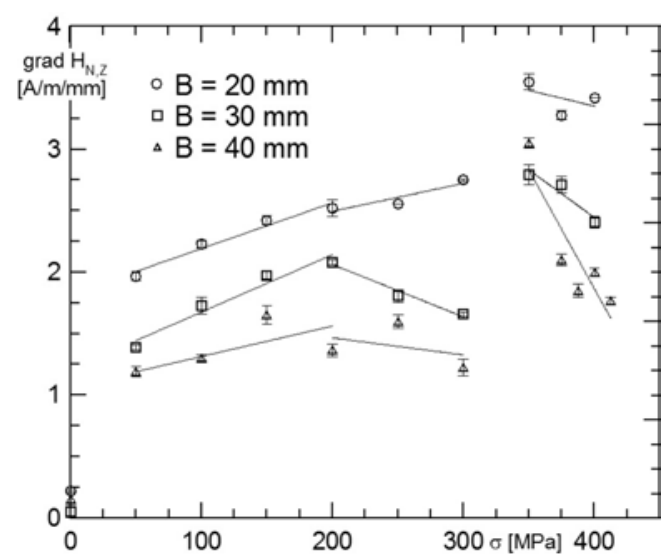

Rys. 5. Zależność średnich wartości gradientów składowych WMPR od naprężeń rozciągających - pomiar po odciążeniu: a) gradient średni składowej stycznej $\mathrm{H}_{\mathrm{T}, \mathrm{Y}}$, b) gradient średni składowej normalnej $\mathrm{H}_{\mathrm{N}, \mathrm{Z}}$

Fig. 5. Dependence of the average values of gradients of the RMF components on tensile stress - measurement after unloading: a) average gradient of the tangential component $\mathrm{H}_{\mathrm{T}, \mathrm{Y}}$, b) average gradient of the normal component $\mathrm{H}_{\mathrm{N}, \mathrm{Z}}$

\section{Podsumowanie}

Przedstawiono wyniki badań wpływu geometrii na WMPR próbek wykonanych ze stali 16 Mo3. Analizowano zmiany wartości składowych WMPR oraz ich gradientów dla różnych poziomów wytężenia materiału.

Jeśli chodzi o wartości składowych WMPR, to relację z zadanymi obciążeniami można opracować dla składowej stycznej. W relacji tej dominuje wpływ historii obciążenia - naprężeń, choć wpływ geometrii też jest widoczny. Pomiar składowej stycznej zgodnie z kierunkiem działania naprężeń głównych można wykorzystać do celów monitoringu stanu wytężenia konstrukcji wykonanych ze stali ferromagnetycznych.

Wpływ geometrii próbek na wartości gradientów średnich i maksymalnych jest znaczący. Nie można go pomijać przy opracowywaniu wartości granicznych kryteriów oceny w metodzie MPM, stąd też metodyka tej metody wymaga poprawy i uzupełnienia. 


\section{Literatura}

[1] Deputat J.: Podstawy metody magnetycznej pamięci metalu. Dozór Techniczny 5/2002 s. 97-105.

[2] Dietrych J.: System i konstrukcja, Wydawnictwa NaukowoTechniczne, Warszawa 1978.

[3] Roskosz M.: Kryteria oceny w metodzie magnetycznej pamięci metalu, Przegląd Spawalnictwa 13/2012 s. 31-34.

[4] Roskosz M.,Bieniek M.: Analysis of the universality of the residual stress evaluation method based on residual magnetic field measurements, NDT\&E International 54 (2013) 63-68 http://dx.doi.org/10.1016/j.ndteint.2012.12.004.

[5] Roskosz M.: Wpływ naprężeń czynnych i resztkowych na własne pole magnetyczne ferromagnetyków, Przegląd Spawalnictwa $13 / 2011$ s. 46-49.

[6] Roskosz M., Bieniek M.: Evaluation of residual stress in ferromagnetic steels based on residual magnetic field measurements NDT\&E International 45 (2012) 55-62, doi:10.1016/j. ndteint.2011.09.007.
[7] Iwaniec M., Witoś M., Roskosz M., Gontarz S.: Diagnozowanie konstrukcji wsporczych linii WN z wykorzystaniem efektów magneto-mechanicznych, 4 Konferencja NaukowoTechniczna „Diagnostyka Materiałów i Urządzeń Technicznych", Gdańsk 2012

[8] Roskosz M., Bieniek M.: Analysis of the methodology of the assessment of the technical state of a component in the method of metal magnetic memory testing, Proceedings Defektoskopie 2010/ NDE for Safety, p.229-236.

[9] Augustyniak M., Roskosz M. Hierarchia czynników wpływu w diagnostyce metodą statycznego pola rozproszonego, 41 Krajowa Konferencja Badań Nieniszczących, Toruń 2012.

[10] PN-ISO 24497-1, 2, ,3 Badania nieniszczące - Magnetyczna pamięć metalu -- Część 1: Słownictwo, Część 2: Wymagania ogólne, Część 3: Kontrola złączy spawanych.

[11] Własow W.T., Dubow A.A: Ocena poziomu naprężeń w strefach ich koncentracji według metody magnetycznej pamięci metalu. XIV Seminarium Nieniszczące Badania Materiałów, Zakopane 2008.

\section{Podziękowanie}

Przedstawione $w$ artykule wyniki zostały uzyskane w badaniach wspóffinansowanych przez Narodowe Centrum Badań i Rozwoju w ramach umowy SP/E/1/67484/10 - Strategiczny Program Badawczy - Zaawansowane technologie pozyskiwania energii: Opracowanie technologii dla wysokosprawnych „zero-emisyjnych” bloków węglowych zintegrowanych z wychwytem $\mathrm{CO}_{2}$ ze spalin.

\section{Przegląd Spawalnictwa}

\section{www.pspaw.pl pspaw@ps.pl}

\section{ARTYKUKY ARCHIWALNE PRZEGLADU SPAWALNICTWA}

\section{Cena}

Cena 1 artykułu z numeru archiwalnego w wersji elektronicznej: 21 zł (w tym 5\% VAT)

\section{W celu zamówienia artykułu należy wypełnić formularz zamieszczony obok i przesłać go w formie skanu wraz $z$ potwierdzeniem wpłaty adres:}

$$
\text { pspaw@ps.pl }
$$

Wpłaty należy dokonać na rachunek bankowy: Bank BPH S.A. Oddział w Warszawie 45106000760000320000431836

\section{Artykuły wysyłane są drogą elektroniczną} w ciągu 2 dni od otrzymania zamówienia.

\section{REDAKCJA - Przegląd Spawalnictwa AW SIMP}

ul. Świętokrzyska 14a, 00-050 Warszawa tel.: 2282725 42, faks: 223361479

\section{Zamawiam artykuły:}

Nr zeszytu: ..........., rok ............., strony

Nr zeszytu: strony

Nr zeszytu: strony

Adres e-mail

Imię i nazwisko

Firma

Adres

NIP

Kontakt do osoby zamawiającej:

Oświadczam, że jestem podatnikiem VAT i upoważniam firmę do wystawienia faktury bez podpisu 